\title{
3D STRUCTURE OF SAHARAN DUST Transport TOWARdS EUROPE AS SEEN BY CALIPSO
}

\author{
Eleni Marinou ${ }^{1 *}$, Vassilis Amiridis ${ }^{1}$, Alexandra Tsekeri ${ }^{1}$, Stavros Solomos ${ }^{1}$, Panos Kokkalis ${ }^{1}$, \\ Emmanouil Proestakis ${ }^{1}$, Michael Kottas ${ }^{1}$, Ioannis Binietoglou ${ }^{2}$, Prodromos Zanis ${ }^{3}$, Stelios Kazadzis ${ }^{4}$, \\ Ulla Wandinger ${ }^{5}$ and Albert Ansmann ${ }^{5}$ \\ ${ }^{1}$ IAASARS, National Observatory of Athens, Athens, Greece, *Email: elmarinou@noa.gr \\ ${ }^{2}$ National Institute of $R \& D$ for Optoelectronics, Magurele, Romania \\ ${ }^{3}$ Department of Meteorology and Climatology, School of Geology, Aristotle University of Thessaloniki, \\ Thessaloniki, Greece
}

${ }^{4}$ Physikalisch-Meteorologisches Observatorium Davos, World Radiation Center, Switzerland

${ }^{5}$ Leibniz Institute for Tropospheric Research, Leipzig, Germany

\begin{abstract}
We present a 3D multi-year monthly mean climatology of Saharan dust advection over Europe using an area-optimized pure dust CALIPSO product. The product has been developed by applying EARLINET-measured dust lidar ratios and depolarization-based dust discrimination methods and it is shown to have a very good agreement in terms of AOD when compared to AERONET over Europe/North Africa and MODIS over Mediterranean. The processing of such purely observational data reveals the certain seasonal patterns of dust transportation towards Europe and the Atlantic Ocean. The physical and optical properties of the dust layer are identified for several areas near the Saharan sources, over the Mediterranean and over continental Europe.
\end{abstract}

\section{INTRODUCTION}

CALIPSO is capable of providing a multi-year, robust 4D dust climatology, a task that cannot easily be achieved by passive sensors, especially over bright surfaces like deserts. However, limitations on retrieval performance using CALIPSO exist, especially regarding the classification of dust and its mixtures based on the approximate particle depolarization ratio and the retrieval of the dust extinction that is based on the Lidar Ratio (LR) assumption.

Amiridis et al. (2013) [1] demonstrated a method for the retrieval of pure dust extinction from CALIPSO based on a depolarization-based separation of pure dust backscatter fraction in dusty mixtures (Tesche et al., 2009) and the application of a regionally uniform LR for calculating dust extinction. This LR value (equal to $58 \mathrm{sr}$ ) has been taken from climatological values derived by long-term EARLINET measurements. It has been shown in [1] that the final dust product is consistent with AERONET collocated measurements over Sahara and Europe and also consistent with MODIS over the Mediterranean for collocated cells with low cloudiness.

Here, we present a climatology of the Saharan dust 3D structure and load over Europe and North Africa based on the product introduced and validated in [1]. We briefly present the methodology in section 2, demonstrate the first results in section 3 and conclusions in section 4 .

\section{METHODOLOGY}

We produce a monthly mean dust L3 product based on averaging CALIPSO L2 product following the methodology introduced in [1]. In brief, the product is developed using the filtering CALIPSO techniques introduced in [2]. The product aggregation is performed in a $1 \mathrm{x} 1$ degree spatial resolution for the backscatter coefficient at $532 \mathrm{~nm}$. Prior averaging, we obtain the dust backscatter coefficient for pure dust by applying the method introduced in [3]. This method makes use of the particle backscatter coefficient and the particle depolarization ratio at $532 \mathrm{~nm}$ in order to separate the backscatter contributions of the weakly depolarizing aerosol components ("other type") from the contribution of strongly depolarizing particles (pure dust). We avoid using the polluted dust and pure dust CALIPSO types in order to eliminate possible misclassifications 
introduced due to the use of L1 estimation of the depolarization ratio. Instead, we use the L2 linear particle depolarization ratio (recalculated from L2 total and perpendicular backscatter at $532 \mathrm{~nm}$ ) to classify dust and polluted dust components following the definitions given in [1]. After discriminating the pure dust from its mixtures with other types, we apply the EARLINET-based climatological dust LR of $58 \mathrm{sr}$ on each backscatter profile prior averaging. Finally, we apply a slightly different concept on averaging the dust extinction on the $1 \mathrm{x} 1$ degree resolution, by acknowledging zero extinction contribution from the "other" non-dust aerosol types. This alteration would result on a product that is representative of the dust extinction and correspondingly the dust columnar AOD in regard to the total AOD. In other words, we calculate the dust AOD contribution to the total AOD.

The methodology introduced in [1] and applied here on CALIPSO record between the years 2007 and 2014, has been validated against AERONET over land and compared to MODIS over the Mediterranean. A demonstration of those evaluations is given in the following figures.
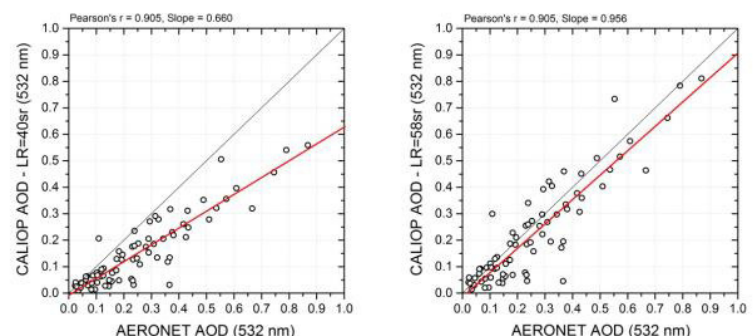

Figure 1: Scatter plot comparison of CALIPSO AOD versus collocated AERONET measurements when LR is equal to $40 \mathrm{sr}$ (left) and when LR is equal to $58 \mathrm{sr}$ (right).
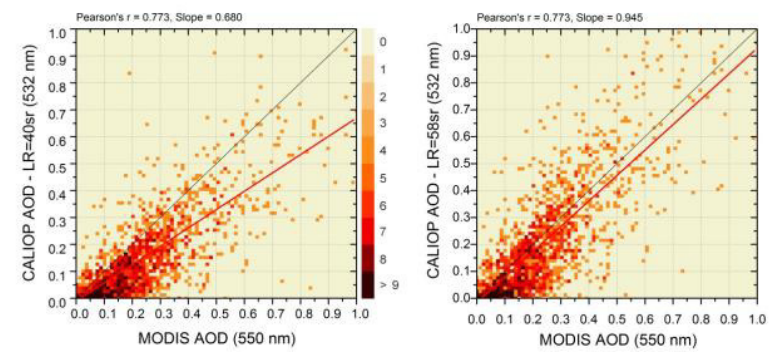

Figure 2: Comparison of CALIPSO AODs (1x1 degree) versus collocated MODIS-Aqua Level 3 product using LR equal to $40 \mathrm{sr}$ (left) and LR equal to 58 sr (right). The 2D scatterplots represent the number of cases found for each CALIPSO/MODIS AOD bin between 0 and 1.0 (bin step equal to 0.0125). MODIS data are not filtered, while CALIPSO data are filtered according to CAL-L3 specifications. Only CALIPSO overpasses that are cloud-free and for which the aerosol classification scheme reveals only dust presence are considered.

\section{RESULTS}

From the CALIPSO dust product we provide here a climatology for the domain between 20 and 60 in latitude and between -20 and 30 in longitude which includes Europe and North Africa and where we believe that the EARLINET-derived LR value of $58 \mathrm{sr}$ can be applied. In Figure 3 we present a seasonal distribution of the dust AOD in the Region of Interest (RoI).The four seasons are defined based on the dominant dust transportation patterns. During January to March (J-F-M) limited dust activity is observed almost uniformly over Sahara and the AOD remains below 0.2 with the exception of specific dust hot-spots. The formation of mid-latitude low pressure systems during this period results in transportation of dust from the deserts of Libya towards Greece and a mean seasonal AOD of $0.15-0.2$ is found over eastern Mediterranean. For the period April-June (A-M-J) dust production is evident over the entire desert and AOD values exceeding 0.5 are found especially at lower latitudes $\left(20^{\circ} \mathrm{N}-30^{\circ} \mathrm{N}\right)$. Over central and eastern Mediterranean, South Italy, Greece and Turkey the mean CALIPSO dust AOD is close to 0.15. During July-September (JA-S) dust activity is mostly limited to the western part of the Sahara and the AOD near the sources is up to 0.6. The migration of the ITCZ (Intertropical Convergence Zone) towards higher latitudes and the dominance of trade wind patterns (easterlies) favor the transportation of dust towards the Atlantic Ocean. Increased AOD values up to 2 are also found over western Mediterranean, south Italy and the south coast of Spain. For October up to December (O-N-D) dust activity is mostly suppressed except from the south-west desert areas close to the Sahel zone where AOD remains close to $0.3-0.4$. 

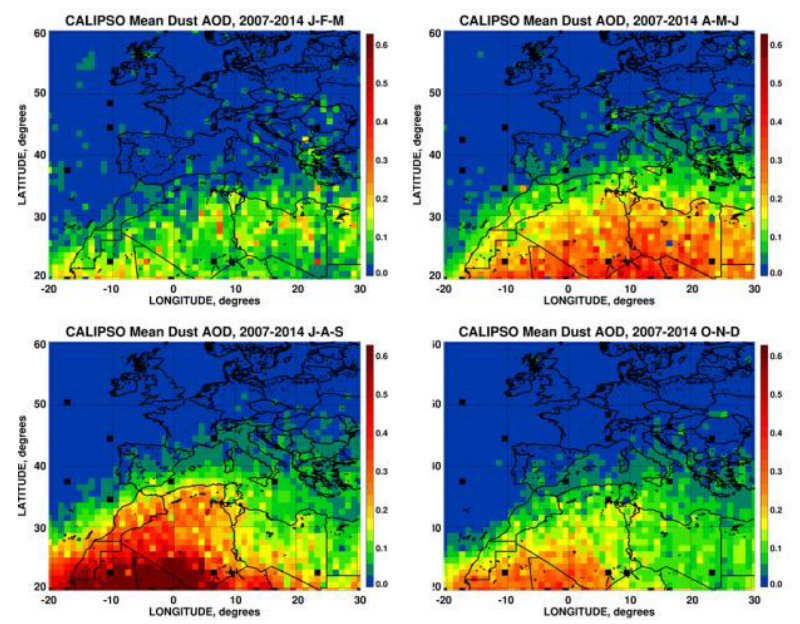

Figure 3: Dust AOD of 1x1 degree spatial resolution averaged for the four seasons over RoI using CALIPSO observations from 2007 to 2014.

In Figure 4 we present the Top Layer Height (TLH) of the dust layer produced from the averaged profiles within the $1 \times 1$ degree cells. During the first period (J-F-M) dust remains in general below 3-4 $\mathrm{km}$ over land areas. Over the sea, several transport paths are evident and dust extends higher than $3 \mathrm{~km}$. In A-M-J the dust layer top is up to $6 \mathrm{~km}$ over Africa and up to 3-4 km over the sea and south Europe. The highest top layer values $(>8 \mathrm{~km})$ are found for the period $(\mathrm{J}-$ A-S) over west Africa and Atlantic Ocean. Intrusion of the lower tropospheric Atlantic monsoon south of the ITCZ and the development of MCS (mesoscale-convective systems) favor the elevation of dust at this area and the transatlantic transportation of dust along the easterlies. During the same period, the dominance of the strong Saharan high favors mobilization of dust from the western part of Sahara towards west Mediterranean and Europe. This pattern leads to elevated dust up to 3-4 km over south European countries and the Balkans. In O-N-D the situation is similar to A-M-J however with relatively lower heights.
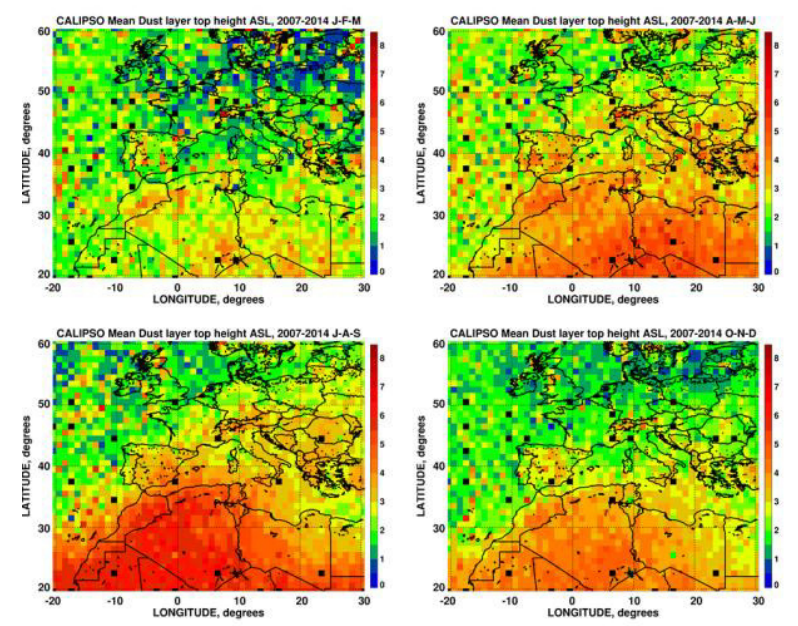

Figure 4: Seasonal maps of dust Top Layer Height $(\mathrm{km})$ over the RoI using CALIPSO observations from 2007 to 2014.
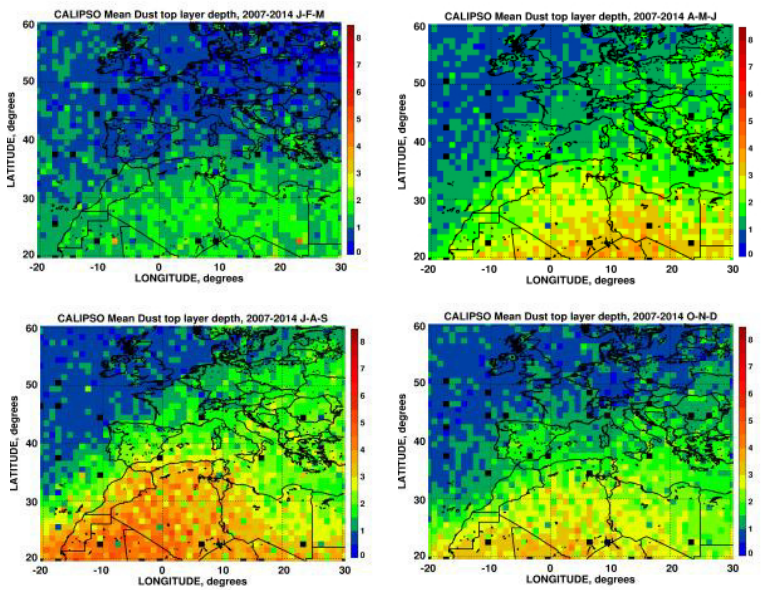

Figure 5: Seasonal maps of the Dust Layer Depth over the RoI using CALIPSO observations from 2007 to 2014.

The dust layer thickness (Figure 5) is an important parameter for determining the severity of dust episodes over certain areas and also the vertical structure of dust plumes. This last parameter is of particular importance for radiative transfer calculations and dust-cloud interactions. As seen in this figure, the dust plumes that affect Europe are at the range of $1-2.5 \mathrm{~km}$ in depth while dust plumes off the west African coast can be 5-6 km thick. 


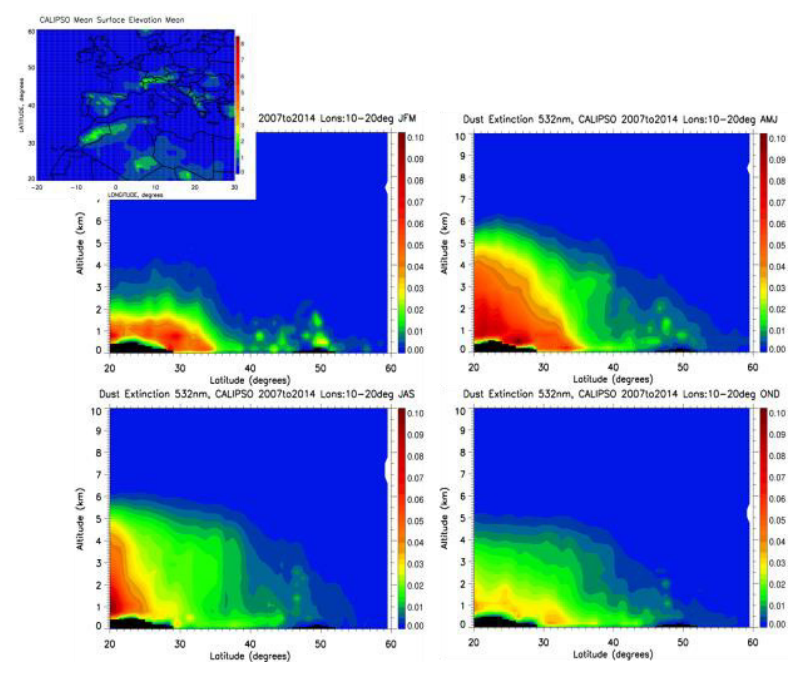

Figure 6: Seasonal maps of dust extinction cross sections for the longitudinal belt between 10 and 20 degrees using CALIPSO observations from 2007 to 2014.

A very important asset of this particular CALIPSO dust product is the three-dimensional information on dust extinction that is seen for example at the vertical South-to-North crosssections of Figure 6 for the area between $10^{\circ} \mathrm{E}$ $20^{\circ} \mathrm{E}$. This region includes the dust sources of Libya and central Sahara, central Mediterranean, Italy, the Alps and part of North Europe. It is evident from this figure that dust extinction over central Mediterranean $\left(30^{\circ} \mathrm{N}-45^{\circ} \mathrm{N}\right)$ is higher than 0.02 throughout the year. Moreover, elevated dust is seen over the Alps $\left(47^{\circ} \mathrm{N}-52^{\circ} \mathrm{N}\right)$ and significantly high values $(>0.03)$ are especially found for the period J-F-M.

\section{CONCLUSIONS and FUTURE WORK}

CALIPSO is capable of providing a multi-year, robust 4D dust climatology, a task that cannot easily be achieved by passive sensors, especially over deserts. However, limitations on retrieval performance using CALIPSO exist, especially regarding the classification of dust and its mixtures based on the approximate particle depolarization ratio and the LR assumption. In this paper, we brief our previous work on the potential improvement of CALIPSO dust retrievals over Europe and North Africa by using a dust LR of $58 \mathrm{sr}$, demonstrating that a regional correction is feasible when using a universal and spatially constant LR. Then, we demonstrate the potential of this product to provide pure dust $2 \mathrm{D}$ and 3D distributions over the RoI. Future work includes the application of the methodology in similar studies over the deserts in the Middle East and China in order to optimize CALIPSO dust retrievals over these areas as well. Ground-based measurements of the dust LR and particle depolarization ratio for these regions will be vital for the success of implementing similar improvements.

\section{ACKNOWLEDGEMENT}

The publication was supported by the European Union Seventh Framework Programme (FP7REGPOT-2012-2013-1), in the framework of the project BEYOND, under Grant Agreement no. 316210 (BEYOND - Building Capacity for a Centre of Excellence for EO-based monitoring of Natural Disasters). The research leading to these results has received funding from the European Union Seventh Framework Programme (FP7/2007-2013) under grant agreement no. 262254 (ACTRIS). The research leading to these results has received funding from the European Union Seventh Framework Programme (FP7/2007-2013) under grant agreement $\mathrm{n}^{\circ}$ 606953 (MarcoPolo). CALIPSO data were provided by NASA. We thank the ICARE Data and Services Center for providing access to the data used in this study.

\section{REFERENCES}

[1] Amiridis, V., et al., 2013: Optimizing CALIPSO Saharan dust retrievals, Atmos. Chem. Phys., 13, 12089-12106, doi:10.5194/acp-1312089-2013.

[2] Winker, D. M., et al., 2013: The global 3-D distribution of tropospheric aerosols as characterized by CALIOP, Atmos. Chem. Phys., 13, 3345-3361, doi:10.5194/acp-13-3345-2013.

[3] Tesche, M., et al., 2009: Vertically resolved separation of dust and smoke over Cape Verde using multiwavelength Raman and polarization lidars during Saharan Mineral Dust Experiment 2008, Journal of Geophysical Research D: Atmospheres, 114 (13), D13202, doi: 10.1029/2009JD011862. 